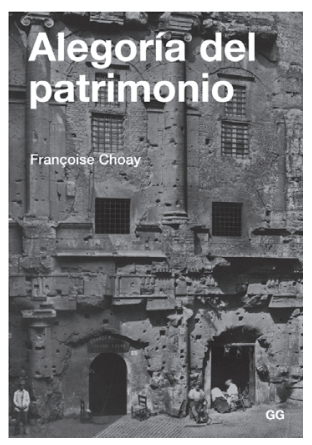

\title{
Choay, Françoise. Alegoría del patrimonio
}

\author{
Barcelona: Gustavo Gili, 2007. 263 p.
}

\author{
Gerard Jori ${ }^{1}$
}

Desde los años ochenta, la conservación y la valorización del patrimonio urbano han ido adquiriendo un carácter cada vez más prioritario en las políticas urbanas. La emergencia en el urbanismo de planteamientos favorables a las tramas densas y mixtas o la opción estratégica que muchas ciudades han hecho por el turismo, son fenómenos que contribuyen a explicar esta creciente preocupación por el patrimonio histórico y cultural. Sin embargo, la inserción del patrimonio en la ciudad contemporánea no está ni mucho menos exenta de problemas, entre los que se pueden señalar la musealización de centros históricos, la destrucción de tejidos antiguos o los impactos negativos ocasionados por la afluencia masiva de turistas. Las actuaciones de los políticos y técnicos no siempre han sido todo lo respetuosas que cabría esperar y en demasiadas ocasiones han implicado una auténtica banalización del patrimonio urbano. Es preciso juzgar críticamente muchas de las actitudes oficiales y denunciar aquellas intervenciones que no sean lo suficientemente cuidadosas con la herencia construida de la ciudad.

Para ello, debemos interrogarnos acerca del sentido amplio que tiene el patrimonio urbano, pues solo conociendo su razón de ser profunda nos será posible plantear actuaciones de altas miras. Más allá de contribuir al conocimiento de la historia del arte, o de ser uno de los productos predilectos de la moderna industria del ocio, el patrimonio

\footnotetext{
1 Doctorando en la Universidad de Barcelona. Becario del Programa de Formación del Profesorado Universitario del Ministerio de Ciencia e Innovación (España). E-mail: gerardjori@gmail.com
}

encierra unos valores que rebasan lo puramente estético. Se requieren estudios que pongan de manifiesto su marcado significado social, razón por la que hay que celebrar la reciente publicación en castellano del libro Alegoría del patrimonio de Françoise Choay. El texto, cuya primera edición francesa data de 1992, es una obra ya clásica de la caracterización del patrimonio urbano. La autora explora en profundidad su significado a lo largo de los últimos cinco siglos, concluyendo que el sentido que se otorga al patrimonio guarda relación con motivaciones existenciales e informa acerca de las sociedades que lo afirman.

El trabajo comienza diferenciando las nociones de monumento y monumento histórico, que lejos de ser coincidentes mantienen relaciones opuestas con el tiempo, la memoria y el saber. Así, el monumento es universal en el espacio y el tiempo, mientras que el monumento histórico es una invención europea claramente fechada; el monumento es una creación deliberada, mientras que el monumento histórico solo adquiere tal carácter a posteriori; el monumento tiene por finalidad hacer revivir en el presente un pasado superado, mientras que el monumento histórico, en tanto que obra de arte, forma parte del presente vivido sin necesidad de que medie la memoria; y el monumento está expuesto al desinterés u olvido, mientras que el monumento histórico es objeto de conservación.

Los cuatro capítulos siguientes caracterizan la evolución del significado de la noción de monumento histórico "a partir de la fase antiquizante del Quattrocento -cuando los monumentos elegidos pertenecían exclu- 
sivamente a la antigüedad- hasta la fase de consagración que institucionaliza la conservación del monumento histórico" (Choay, 2007: 21). En el quinto capítulo, Choay indaga en la aparición de la noción de patrimonio urbano, que es cuatrocientos años más tardía que la de monumento histórico. Por último, la autora critica severamente las políticas culturales de las últimas décadas y aboga por la protección incondicional de los monumentos históricos y el patrimonio urbano frente a la creciente explotación económica de que son objeto.

Choay sitúa el nacimiento del monumento histórico y los inicios de la conservación en la Roma de la década de 1420. La autora cita numerosos testimonios que dan cuenta del surgimiento de la mirada distanciada y estetizante que, al posarse sobre los edificios, hizo de ellos objetos de reflexión y contemplación. Esta actitud, síntesis de las aproximaciones histórica y artística, es la que llevó a los humanistas del Cuatrocientos a multiplicar las protestas contra el pillaje de los edificios antiguos. Los papas de los decenios sucesivos se harán eco de tales condenas prohibiendo la utilización de las antigüedades como canteras, aunque ellos mismos seguirán extrayendo piedra de aquellas edificaciones para levantar sus propias construcciones. Desajustes de este tipo entre el discurso y la práctica-deseo de conservar y necesidad de construir- se constatan en todas las épocas analizadas en el libro, lo que se explica por la complejidad de las fuerzas contradictorias a las que están sometidos los actores.

La autora se detiene a examinar con detenimiento el significado que la Revolución Francesa dio a los monumentos históricos. De los decretos e instrucciones publicados por el Comité de Instrucción Pública, infiere que se les otorga, ante todo, un valor nacional que es el que legitima a los otros valores -cognitivo, económico y artístico por orden de importancia-, el que justifica la necesidad de inventario y el que inspira las medidas de conservación. En otras palabras, se hace del monumento histórico la memoria viva de la nación. Sin embargo, desde la segunda década del siglo XIX se advierte una inversión en la jerarquía de valores atribuidos a los monumentos históricos ya que, por primera vez, estos son objeto de un interés fundamentalmente estético. La toma de conciencia de la degradación del entorno que provoca la industrialización -junto a otros factores como el romanticismo- hace privilegiar el valor artístico de los monumentos, al tiempo que conduce a un refinamiento de los instrumentos jurídicos y administrativos para protegerlos. Especialmente significativas son, en este sentido, la creación en 1830 del cargo francés de inspector de monumentos históricos y la promulgación en 1887 de la ley gala sobre monumentos históricos, con la que el Estado se dota de una poderosa infraestructura para garantizar su conservación.

Al mismo tiempo, el debate europeo sobre la restauración se enriquece con el enfrentamiento de dos doctrinas antagónicas: la intervencionista, predominante en los países continentales, y la antiintervencionista, propia de Gran Bretaña. Choay analiza detalladamente esta polémica clave en la historia de la restauración. Según el enfoque intervencionista, cuyo mayor exponente fue el arquitecto Eugène-Emmanuel Viollet-le-Duc, "restaurar un edificio es restablecer un estado completo que puede no haber existido nunca" (Choay, 2007: 134). Esta postura se funda en una concepción ideal o abstracta del monumento histórico, que lleva a afirmar que la restauración no tiene por qué tener en cuenta la autenticidad del objeto restaurado. En cambio, para los antiintervencionistas, representados por John Ruskin, restauración y conservación son nociones incompatibles porque la pátina del tiempo forma parte de la esencia del monumento histórico. En su concepción más radical, esta doctrina postula que toda intervención es un sacrilegio porque el destino irremediable del monumento es la ruina. El mérito de la autora consiste en interpretar el pensamiento de Camillo Boito como una elaborada síntesis de ambas posturas. Este arquitecto, escritor y crítico de arte italiano no niega que haya que intervenir en los edificios cuando estudios exhaustivos así lo aconsejen, pero siempre es preciso respetar tanto su singularidad, como la pátina que el tiempo ha posado sobre ellos. Lo que, entre otras cosas, implica adoptar el criterio de mínima intervención y diferenciar ostensiblemente las partes correspondientes a las obras de restauración. 
Respecto a la invención del patrimonio urbano, Choay apunta que en la génesis de dicho concepto se encuentra la conversión de la ciudad antigua en un objeto de saber histórico, lo que solo pudo tener lugar a raíz de la transformación del espacio urbano que provocó la industrialización. Hasta que no se hizo patente la diferenciación entre la ciudad histórica y la ciudad industrial aqueIla no pudo ser considerada en su conjunto $y$, por tanto, pensada como un objeto de conservación en su totalidad. Lo que lleva a la autora a afirmar que "la noción de patrimonio urbano histórico se construye a contracorriente del proceso de urbanización dominante" (Choay, 2007: 164); y añade que es el resultado de una dialéctica de la historia con la historicidad que implica tres miradas cronológicamente sucesivas a la ciudad antigua: memorial, histórica e historial.

El primero de estos enfoques -el memorial- es el que se desprende de los textos de Ruskin. Una de sus innovaciones fundamentales fue considerar el tejido urbano antiguo como una entidad específica. Para Ruskin, el conjunto de la ciudad preindustrial configura una armonía de la que participan tanto los edificios de arquitectura culta como los de arquitectura vulgar o doméstica, lo que le impide concebir los primeros desligados de los segundos. Además, toda la ciudad antigua posee para Ruskin el carácter de monumento en el sentido original y etimológico del término, ya que apela a la memoria colectiva y habla acerca de los hombres que la habitaron. Sin embargo, Ruskin es incapaz de situar estos descubrimientos en su perspectiva histórica, pues en vez de abogar por la conservación de la ciudad preindustrial en tanto que monumento histórico con una función memorial, propugna, mediante una argumentación que en realidad es profundamente antihistórica, una vuelta a la sociedad del pasado.

Choay cita a Camillo Sitte como el mayor exponente de la aproximación histórica a la ciudad preindustrial. En 1889 publicó un pequeño ensayo titulado "Construcción de ciudades según principios artísticos" en el que se constatan los inconvenientes estéticos que presenta la ciudad contemporánea. El objetivo de Sitte radica en mostrar en qué medida la ciudad moderna podría irradiar belleza plástica a partir de lecciones extraídas de la ciudad antigua. No obstante, Choay señala que el modelo ideado por el maestro vienés plantea una antinomia irresoluble, dado que propone crear racional y deliberadamente unas formas que en el pasado fueron producidas orgánicamente. El mismo Sitte es consciente del carácter fingido que tendría un paisaje natural y artificial al mismo tiempo, aunque no es capaz de salvar esta dificultad.

El libro de Sitte se centra casi con exclusividad en la función propedéutica que tiene la ciudad del pasado, pero de él se infiere otro importante tema al que el arquitecto apenas prestó atención: el de la conservación de los tejidos antiguos. Serán los seguidores del vienés quienes lo desarrollarán, atribuyendo a la ciudad preindustrial una función museal. Más que concebir el espacio urbano como un museo, con ello la autora quiere dar a entender que el conjunto urbano es concebido como una pieza de museo, carácter que le viene dado por ser un objeto raro, frágil, bello y en trance de desaparecer. Sin embargo, como toda obra expuesta en un museo, la ciudad antigua debe, con arreglo a esta visión, desligarse de los circuitos de la vida cotidiana y desprenderse de sus usos y habitantes. Lo que lleva a la autora a afirmar que "al transformarse en histórica, la ciudad pierde su historicidad" (Choay, 2007: 172).

Gustavo Giovannoni, inventor, según Choay, del término "patrimonio urbano", fue quien halló la forma de sintetizar y superar las aproximaciones precedentes mediante un enfoque que la autora califica de historial. Este italiano tenía una triple formación. Como ingeniero, intuyó desde la segunda década del Novecientos que la implantación de las grandes redes de comunicación y telecomunicación acarrearía un proceso de desintegración de la ciudad densa en beneficio de una urbanización difusa y a escala territorial; como arquitecto, comprendió que la nueva sociedad no podría funcionar únicamente a escala territorial, sino que requeriría unidades de vida a escala local; y como historiador del arte estableció que la ciudad preindustrial, aun teniendo un papel memorial, propedéutico y museal, podía igualmente desempeñar aque- 
Ila función, pues su forma y dimensión hacen de ella un lugar idóneo para albergar determinados usos contemporáneos "de proximidad". De este modo, Giovannoni otorga a la ciudad antigua el valor de uso para el presente que otros le habían negado, justificando la conservación del patrimonio sin la necesidad de congelarlo.

La aproximación que propone Giovannoni es el punto de llegada de la historia de la construcción del concepto de patrimonio urbano que describe Choay. Con posterioridad, se han producido importantes aportaciones conceptuales y metodológicas, pero estas siguen en buena medida enmarcándose en la mirada historial del italiano a la ciudad antigua. En cambio, lo que sí puede ser considerado como una novedad es la necesidad de proteger el patrimonio urbano frente a las agresiones que comporta su creciente explotación económica. Choay dedica la última parte del libro a abordar esta cuestión, postulando la necesidad de adop- tar medidas estratégicas -creación de réplicas para proteger los originales, control de flujos turísticos, etc.- contra los efectos perversos del uso masivo del patrimonio.

Para concluir, conviene apuntar que "Alegoría del patrimonio" es una obra profundamente francocéntrica. La misma autora advierte en la introducción que buena parte de sus ejemplos están tomados de Francia, aunque el problema, desde mi punto de vista, no reside aquí sino en la omisión de importantes tradiciones europeas e iberoamericanas. Así, por poner un ejemplo, no menciona el vivo debate que se planteó en España desde comienzos del tercer decenio del siglo XIX, cuando románticos como José $M^{a}$ Quadrado relacionaron la destrucción de monumentos históricos con la degradación moral del siglo. Pese a ello, el libro sigue constituyendo, tras más de quince años desde su aparición, una obra clave para comprender el significado del patrimonio urbano y la necesidad de estudiarlo y protegerlo. 